Acta Crystallographica Section E

Structure Reports

Online

ISSN 1600-5368

\title{
Zwitterionic 5-amino-2-naphthalenesulfonic acid
}

The crystal structure of 5-amino-2-naphthalenesulfonic acid (1,6-Cleve's acid), $\mathrm{C}_{10} \mathrm{H}_{9} \mathrm{NO}_{3} \mathrm{~S}$, shows the presence of a sulfonate-aminium group zwitterion, viz. 5-ammonio-2naphthalenesulfonate. All aminium $\mathrm{H}$ atoms are involved in head-to-tail intermolecular hydrogen-bonding interactions with separate sulfonate $\mathrm{O}$-atom acceptors, giving a threedimensional framework polymer structure.

\section{Comment}

Although the reported structures of benzenesulfonic acids are numerous in the literature, those of polycyclic aromatic sulfonic acids are rare. No amino-substituted naphthalenesulfonic acid structures have been reported [only the cell parameters of some compounds, including the title compound, have been published by Corbridge et al. (1966)], while only a limited number of substituted quinolinesulfonic acids are known, mainly those of the versatile bidentate complexing agent oxine (8-hydroxyquinoline): these are 8-hydroxyquinoline-5-sulfonic acid (a dihydrate) (Banerjee et al., 1984), 8-hydroxy-2-methylquinoline-5-sulfonic acid (a monohydrate) (Merritt \& Duffin, 1970), 8-hydroxy-7-nitroquinoline-5sulfonic acid (Balasubramanian \& Muthiah, 1996) and 8hydroxy-7-iodoquinoline-5-sulfonic acid (Ferron) (Merritt \& Duffin, 1970; Balasubramanian \& Muthiah, 1996). With the sulfonic acids, the structures commonly incorporate water of solvation which is involved in intermolecular hydrogen bonding through the sulfonate $\mathrm{O}$ atoms. However, with acids having additional interactive secondary functional groups, the potential for structure expansion through hydrogen bonding is increased.<smiles>[NH3+]c1cccc2cc([Se](=O)([O-])[O-])ccc12</smiles>

(I)

The title compound, 5-amino-2-naphthalenesulfonic acid (1,6-Cleve's acid, ANSA), (I), is an important compound having industrial chemical applications, not only in the manufacture of azo dyes (Stecher, 1968), but as an aniline polymer precursor for the synthesis of co-polymer materials with unusual ferromagnetic and antiferromagnetic properties (Yoshino et al., 1994; Kawai et al., 1994; Galaj et al., 1995; Mizobuchi et al., 1995; Atkinson et al., 2000; Wei \& Wan, 2003). These materials are covered by numerous patents, e.g. Galaj \& Le Mehaute (1995) and Le Mehaute et al. (1995). More recent
Received 4 October 2004 Accepted 6 October 2004 Online 16 October 2004
(C) 2004 International Union of Crystallography Printed in Great Britain - all rights reserved 


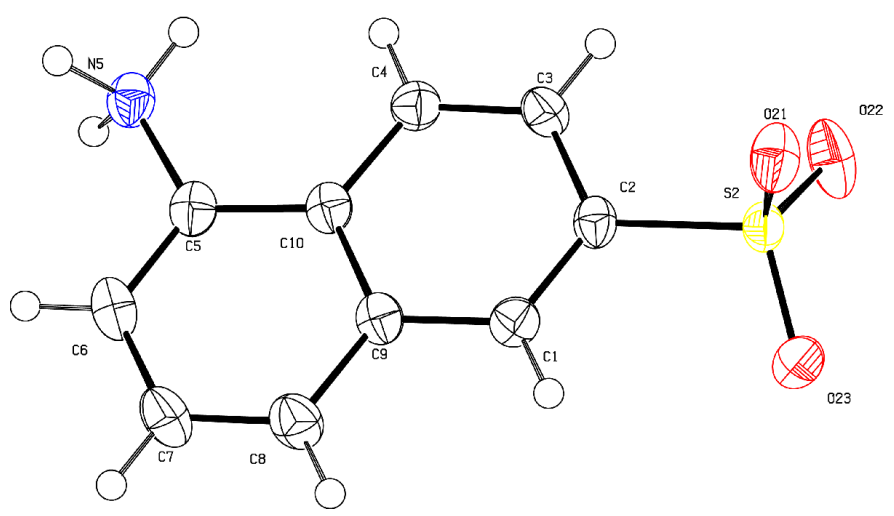

Figure 1

The molecular configuration and atom-numbering scheme for (I), with non- $\mathrm{H}$ atoms shown as $40 \%$ probability ellipsoids

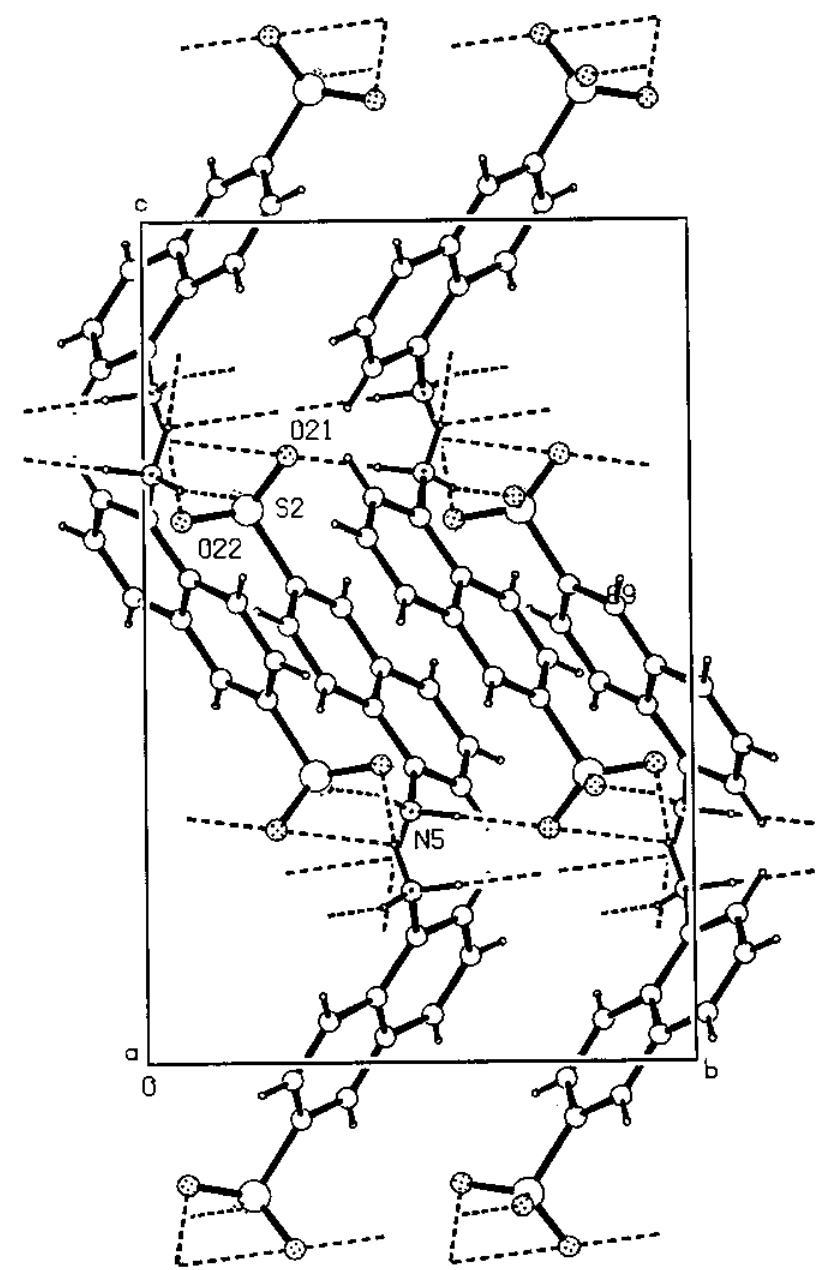

Figure 2

Perspective view of the packing in the unit cell, viewed down the $a$ direction, showing hydrogen-bonding associations as broken lines.

applications include derivatives of (I) with enhanced antiangiogenic activity, the crystal structure of an acidic fibroblast growth factor complexed to $\mathrm{ANSA}^{-}$being determined (Fernandez-Tornero et al., 2003). Although (I) was obtained as a unintentional product in the attempted preparation of a proton-transfer compound, it provided a rare example of a naphthalenesulfonic acid which has, in addition, a secondary

trans-related amino substituent with potential for longitudinal structure extension. Furthermore, (I) is not easily obtained as a crystalline material, having limited solubility in common solvents such as water, ethanol or ethers (Stecher, 1968). The structure of (I) was therefore completed and is reported here.

The individual molecules of (I) show, not surprisingly considering the presence of both sulfonic acid and amino groups, a zwitterionic form with the proton from the 2-sulfonic acid group residing on the 5-amino substituent group of the naphthalene molecule (Fig. 1). This is similar to what was found in orthanilic acid (Hall \& Maslen, 1965), where the amino and acid groups are ortho-related. The substituted quinoline sulfonic acid ferron (8-hydroxy-7-iodoquinoline-5sulfonic acid) (Merritt \& Duffin, 1970; Balasubramanian \& Muthiah, 1996) is also zwitterionic, with the hetero $\mathrm{N}$ atom protonated. The aminium protons in (I) give structure extension via intermolecular head-to-tail hydrogen-bonding interactions with the sulfonate O-atom acceptors of three separate acid molecules, including an asymmetric three-centre $R_{1}^{2}(4)$ association with $\mathrm{H} 5 \mathrm{C}$ [to O21 $1^{\text {iii }}$ at 3.141 (3) $\AA$ and to $\mathrm{O} 22^{\mathrm{iii}}$ at 2.823 (3) $\AA$; symmetry code: (iii) $\left.x, \frac{1}{2}-y, z-\frac{1}{2}\right]$. These interactions (Table 1) give expansion of the structure in all axial directions, resulting in an extensive hydrogen-bonded framework polymer (Fig. 2).

\section{Experimental}

The title compound, (I), was isolated as violet-coloured crystals from the attempted preparation of a proton-transfer compound of 5amino-2-naphthalenesulfonic acid with strychnine, by heating for 10 min under reflux $1 \mathrm{mmol}$ quantities of the two reactants in $50 \%$ ethanol/water. The crystals formed as the major product after partial room-temperature evaporation of the hot-filtered solution.

\section{Crystal data \\ $\mathrm{C}_{10} \mathrm{H}_{9} \mathrm{NO}_{3} \mathrm{~S}$ \\ $M_{r}=223.24$ \\ Orthorhombic, Pbca \\ $a=11.120(2) \AA$ \\ $b=10.529(2) \AA$ \\ $c=16.253(3) \AA$ \\ $V=1902.9(6) \AA^{3}$ \\ $Z=8$ \\ $D_{x}=1.558 \mathrm{Mg} \mathrm{m}^{-3}$ \\ $\mathrm{Cu} K \alpha$ radiation \\ Cell parameters from 25 reflections \\ $\theta=15-20^{\circ}$ \\ $\mu=2.93 \mathrm{~mm}^{-1}$ \\ $T=295(2) \mathrm{K}$ \\ Block, violet \\ $0.30 \times 0.20 \times 0.20 \mathrm{~mm}$}

\section{Data collection}

Enraf-Nonius CAD-4F four-circle diffractometer

$\omega-2 \theta$ scans

2124 measured reflections

1725 independent reflections

1496 reflections with $I>2 \sigma(I)$

$R_{\text {int }}=0.033$

\section{Refinement}

Refinement on $F^{2}$

$R\left[F^{2}>2 \sigma\left(F^{2}\right)\right]=0.039$

$w R\left(F^{2}\right)=0.105$

$S=1.06$

1725 reflections

149 parameters

$\mathrm{H}$ atoms treated by a mixture of independent and constrained refinement 
Table 1

Hydrogen-bonding geometry $\left(\AA{ }^{\circ}\right)$.

\begin{tabular}{lllll}
\hline$D-\mathrm{H} \cdots A$ & $D-\mathrm{H}$ & $\mathrm{H} \cdots A$ & $D \cdots A$ & $D-\mathrm{H} \cdots A$ \\
\hline $\mathrm{N} 5-\mathrm{H} 5 A \cdots \mathrm{O} 23^{\mathrm{i}}$ & $0.90(3)$ & $1.97(3)$ & $2.852(3)$ & $165(3)$ \\
$\mathrm{N} 5-\mathrm{H} 5 B \cdots \mathrm{O} 21^{\text {ii }}$ & $1.00(3)$ & $1.80(3)$ & $2.767(3)$ & $161(3)$ \\
$\mathrm{N} 5-\mathrm{H} 5 C \cdots \mathrm{O} 21^{\text {iii }}$ & $1.00(5)$ & $2.51(4)$ & $3.141(3)$ & $120(3)$ \\
$\mathrm{N} 5-\mathrm{H} 5 C \cdots \mathrm{O} 22^{\text {iii }}$ & $1.00(5)$ & $1.86(4)$ & $2.823(3)$ & $160(3)$ \\
$\mathrm{C} 1-\mathrm{H} 1 \cdots \mathrm{O} 23$ & 0.93 & 2.59 & $2.937(3)$ & 103 \\
$\mathrm{C} 4-\mathrm{H} 4 \cdots \mathrm{O} 23^{\mathrm{i}}$ & 0.93 & 2.34 & $3.255(3)$ & 168 \\
$\mathrm{C} 7-\mathrm{H} 7 \cdots \mathrm{O} 21^{\text {iv }}$ & 0.93 & 2.55 & $3.290(3)$ & 137 \\
\hline
\end{tabular}

Symmetry codes: (i) $\frac{1}{2}+x, \frac{1}{2}-y, 1-z$; (ii) $1-x, 1-y, 1-z$; (iii) $x, \frac{1}{2}-y, z-\frac{1}{2}$; (iv) $\frac{1}{2}-x, 1-y, z-\frac{1}{2}$.

$\mathrm{H}$ atoms involved in hydrogen-bonding interactions ( $\mathrm{H} 5 A, \mathrm{H} 5 B$ and $\mathrm{H} 5 \mathrm{C})$ were located by difference methods and their positional and isotropic displacement parameters were refined. Other $\mathrm{H}$ atoms were included at calculated positions in the refinement $(\mathrm{C}-\mathrm{H}=0.93 \AA)$ as riding atoms, with $U_{\text {iso }}(\mathrm{H})$ fixed at $1.2 U_{\text {eq }}(\mathrm{C})$.

Data collection: CAD-4 Software (Enraf-Nonius, 1989); cell refinement: CAD-4 Software; data reduction: XCAD4 (Harms \& Wocadlo, 1995); program(s) used to solve structure: SHELXS97 (Sheldrick, 1997) in WinGX (Farrugia, 1999); program(s) used to refine structure: SHELXL97 (Sheldrick, 1997) in WinGX; molecular graphics: PLATON for Windows (Spek, 1999); software used to prepare material for publication: PLATON for Windows.

The authors acknowledge financial support from the School of Science, Griffith University, and the University of Melbourne.

\section{References}

Atkinson, S., Chan, H. S. O., Neuendorf, A. J., Ng, S. C., Ong, T. T. \& Young, D. J. (2000). Chem. Lett. pp. 276-277.

Balasubramanian, T. \& Muthiah, P. T. (1996). Acta Cryst. C52, 2072-2073.

Banerjee, T., Basak, A. K., Mazumdar, S. K. \& Chaudhuri, S. (1984). Acta Cryst. C40, 507-509.

Corbridge, D. E. C., Brown, C. H. \& Wallwork, S. C. (1966). Acta Cryst. 20, 698-699.

Enraf-Nonius (1989). CAD-4 Software. Version 5.10. Enraf-Nonius, Delft, The Netherlands.

Farrugia, L. J. (1999). J. Appl. Cryst. 32, 837-838.

Fernández-Tornero, C., Lozano, R. M., Redondo-Horcajo, M., Gómez, A. M., López, J. C., Quesada, E., Uriel, C., Valverde, S., Cuevas, P., Romero, A. \& Gimenez-Gallego, G. (2003). J. Biol. Chem. 278, 21774-21781.

Galaj, S., Le Mehaute, A., Tsobnang, F., Cottevieille, D., Liaustic, A., Clement, R., Cagan, V., Guyot, M. \& Fayet, J. C. (1995). J. Magn. Magn. Mater. 140, 1445-1446.

Galaj, S. \& Le Mehaute, A. (1995). Eur. Patent No. EP 645414.

Harms, K. \& Wocadlo, S. (1995). XCAD4. University of Marburg, Germany.

Hall, S. R. \& Maslen, E. N. (1965). Acta Cryst. 18, 301-306.

Kawai, T., Mizobuchi, H. \& Yoshino, K. (1994). Denki Zairyo Gijutsu Zasshi, 3, 74-77.

Le Mehaute, A., Galaj, S., Cottevieille, D., Tsobnang, F. \& Le Fort, F. (1995). Eur. Patent No. EP 680989.

Merritt, L. L. Jr \& Duffin, B. (1970). Acta Cryst. B26, 734-745.

Mizobuchi, H., Kawai, T., Araki, H., Yamasaki, N., Yoshino, K. \& Sakamoto, A. (1995). Syn. Met. 69, 239-240.

Sheldrick, G. M. (1997). SHELXS97 and SHELXL97. University of Göttingen, Germany.

Spek, A. L. (1999). PLATON for Windows. September 1999 Version. University of Utrecht, The Netherlands.

Stecher, P. G. (1968). Editor. The Merck Index, 8th ed., p. 269. Rahway, NJ: Merck and Co.

Wei, Z. \& Wan, M. (2003). J. Appl. Polym. Sci. 87, 1297-1301.

Yoshino, K., Mizobuchi, H., Araki, H., Kawai, T. \& Sakamoto, A. (1994). Jpn J. Appl. Phys. 33, L1624-1627. 